\title{
Structural analysis of the candidate gene that controls awn length in common wheat Triticum aestivum $\mathrm{L}$.
}

\author{
Shcherban A.B.*, Kuvaeva D.D., Salina E.A. \\ Kurchatov Genomic Center of the Institute of Cytology and Genetics, SB RAS, Novosibirsk, Russia \\ *email: atos@bionet.nsc.ru
}

The trait of awness is associated with a number of important, selectively significant plant properties, such as drought resistance, the technological quality of the grain mass during its processing, etc. The main manifestations of this trait are controlled by the B1 locus on the long arm of chromosome 5A. As a result of the previously performed fine mapping, two candidate genes for B1 have been identified, one of which belongs to the vast and poorly understood family of genes encoding transcription factors with the $\mathrm{C} 2 \mathrm{H} 2$ zinc finger domain. We carried out a comparative analysis of the primary structure of this gene in a number of domestic awned and awnless varieties of common wheat T. aestivum L. Along with the absence of polymorphism in the coding region of this gene, we identified 6 SNPs in the promoter region, which, according to our and other data, have a high degree of association with the trait of awness. Based on the identified haplotypes corresponding to the dominant and recessive alleles of the putative B1 gene, we constructed markers for these alleles, which were successfully tested on the material of various varieties of common wheat, $T$. spelta $\mathrm{L}$. wheat lines, as well as on F2/F3 hybrids from crossing between awned and awnless forms of T. aestivum. In the latter case, the correspondence of the established genotypes for B1 to Mendelian segregation by awness was shown.

Acknowledgements: The work was supported by RSF grant No. 21-76-30003. 